\title{
Regional structure-function correlations in chronic obstructive lung disease measured with positron emission tomography
}

Lars H Brudin, Christopher G Rhodes, Sven O Valind, Peter D Buckingham, Terry Jones, J M B Hughes tion such as the diffusing capacity for carbon monoxide (TLCO). ${ }^{124}$ Others have related emphysema to changes in elastic recoil and airway dimensions in lungs at necropsy. ${ }^{5}$ Also, different patterns of the ventilation:perfusion ratio $(\dot{\mathrm{V}} / \dot{\mathrm{Q}})$ have been associated with different clinical presentations of chronic obstructive lung disease, the so called pink and puffing and blue and bloated syndromes. ${ }^{6}$

A more comprehensive analysis is provided by positron emission tomography because regional isotope concentrations can be measured with a much greater degree of accuracy than previously. Also, regional tissue density can be measured and related to ventilation and $\dot{\mathrm{V}} / \mathbf{Q}^{7-10}$ Thus correlations between structure and function can be made in vivo. In this report, 10 patients with chronic obstructive pulmonary disease have been studied to clarify the relation between measurements from positron emission tomography and the different clinical patterns seen in patients with chronic airflow obstruction.

\section{Methods}

SUBJECTS

We studied 10 patients with moderate or severe but stable chronic obstructive lung disease (table 1). Forced expiratory volume in one second $\left(\right.$ FEV $\left._{1}\right)$, vital capacity (VC), total lung capacity (TLC; body plethysmography), and single breath diffusing capacity (TLCO and KCO) were measured with the patient sitting. Functional residual capacity (FRC; supine) was estimated as $R V+0.22$ VC, where $R V$ and $\mathrm{VC}$ are erect residual volume and erect vital capacity respectively. ${ }^{11}$ From these measurements, together with further clinical information, the patients were classified into three categories $^{12}$ : (1) patients $1-4$ with clinical features of type A (emphysematous), (2) patients 7-10 with clinical features of type $B$ (bronchitic), and (3) patients 5-6 with features of both (type $X$ ). In general, the type A patients had minimal sputum production, high TLC, and $\mathrm{KCO}<50 \%$ predicted. The type B patients generally had moderate or severe sputum production, a less pronounced increase in TLC, and KCO $>60 \%$ predicted. All patients had smoked for more than 25 years; none had $\alpha_{1}$ antitrypsin deficiency.

Seventeen subjects free from lung symptoms were also studied to obtain reference values. Eight of these (six men, two women, mean age \begin{abstract}
negative correlation with the ratio $\dot{V} / \dot{Q}$ $(\mathbf{r}=0.55)$ and a positive correlation with $Q(r=0.59)$ and blood volume $(r=0.65)$. In four patients with a low carbon monoxide transfer factor (TLCO) and transfer coefficient (KCO) $<50 \%$ predicted many regions with low VA had low tissue density and normal or high $\dot{V} / \dot{Q}$. On the other hand, in four patients with TLCO and KCO $>50 \%$ predicted many regions with low VA had normal or high tissue density and low values of $\dot{V} / \dot{Q}$. The other two patients had patterns between these two extremes. Individual ratios between mean values of tissue density and $\dot{V} / \dot{Q}$ had a positive correlation with KCO ( $\%$ pred; $r=0.79)$. Conclusions These findings link structural differences with distinctive functional patterns; they reinforce the view that bronchial inflammation or oedema predominate in some patients with chronic airflow obstruction, whereas alveolar destruction is the major feature in others.

(Thorax 1992;47:914-921).

Several recent studies have shown a correlation between a reduced lobar density on radiographic computed tomograms with the amount of emphysema subsequently found on examination of the resected lobe. ${ }^{1-3}$ Correlations have also been sought between computed tomography densities and tests of global lung func-
\end{abstract}

Hospital, S-39185 Kalmar, Sweden

Accepted 15 March 1992 
Table 1 Details of patients studied

\begin{tabular}{|c|c|c|c|c|c|c|c|c|c|c|c|}
\hline Patient & Sex & Height (m) & Age (y) & Type & $\begin{array}{l}\text { TLC } \\
(\% \text { pred })\end{array}$ & $\begin{array}{l}V C \\
\text { (\% pred) }\end{array}$ & $\begin{array}{l}R V \\
(\% \text { pred })\end{array}$ & $\begin{array}{l}F R C^{\star} \\
\text { (\% pred) }\end{array}$ & $\begin{array}{l}F E V_{1} \\
(\% \text { pred })\end{array}$ & $\begin{array}{l}\text { TLCO } \\
\text { (\% pred) }\end{array}$ & $\begin{array}{l}\text { KCo } \\
(\% \text { pred })\end{array}$ \\
\hline 1 & $\mathbf{M}$ & 1.75 & 66 & A & 132 & 97 & 203 & 176 & 38 & 36 & 47 \\
\hline 2 & $M$ & 1.68 & 63 & A & 148 & 57 & 310 & 245 & 17 & 18 & 31 \\
\hline 3 & $\mathbf{F}$ & 1.53 & 52 & A & 91 & 55 & 156 & 130 & 26 & 36 & 42 \\
\hline 4 & $\mathbf{M}$ & $1 \cdot 78$ & 67 & A & 118 & 58 & 228 & 184 & 18 & 21 & 35 \\
\hline 5 & $\mathbf{M}$ & $1 \cdot 88$ & 66 & $\mathbf{X}$ & 86 & 56 & 164 & 132 & 18 & 25 & 56 \\
\hline 6 & $\mathbf{F}$ & 1.48 & 66 & $\mathbf{X}$ & 131 & 87 & 202 & 179 & 50 & 66 & 56 \\
\hline 7 & $\mathbf{M}$ & 1.81 & 62 & B & 111 & 91 & 165 & 144 & 55 & 61 & 67 \\
\hline 8 & $\mathbf{F}$ & 1.50 & 52 & B & 124 & 75 & 213 & 178 & 50 & 93 & 89 \\
\hline 9 & $\mathrm{M}$ & 1.64 & 72 & B & 98 & 78 & 137 & 124 & 46 & 50 & 72 \\
\hline 10 & $F$ & 1.56 & 59 & B & 110 & 61 & 198 & 165 & 43 & 66 & 96 \\
\hline
\end{tabular}

^Estimated values (see text).

TLC—-total lung capacity; VC—vital capacity; RV-residual volume; FRC-functional residual capacity; FEV,-forced expiratory volume in one second; TLCO-carbon monoxide transfer factor; $\mathrm{Kco}-$ transfer coefficient.

34 (range 25-55) years) were never smokers, seven (four men, three women, mean age 49 (range 31-68)) were healthy smokers, and two (one man (age 41), one woman (age 73)) were ex-smokers.

The project was approved by the ethics committee of Hammersmith Hospital and the UK administration of radioactive substances advisory committee. Informed consent was obtained from each subject.

\section{POSITRON EMISSION TOMOGRAPHY}

A positron scanner (ECAT II, CTI, Knoxville) with a spatial resolution of $1.7 \mathrm{~cm}$ was used. A quantitative topographical distribution of total tissue density (DTOT) was obtained with the scanner in the transmission mode. ${ }^{7}$ This information corrected the emission scan for losses due to attenuation of the emitted photons. In the emission mode, a scan was recorded after the introduction of a positron emitting isotope into the body. With appropriate calibration the topographic distribution of the isotope within the tomographic slice was obtained.

\section{COMPUTATION OF PHYSIOLOGICAL VARIABLES}

Regional pulmonary blood volume was determined with inhaled ${ }^{11} \mathrm{C}$ carbon monoxide $\left({ }^{11} \mathrm{CO}\right)$. Simultaneous measurement of ${ }^{11} \mathrm{CO}$ concentration in whole blood allows the fractional pulmonary blood volume (VB; expressed as $\mathrm{ml} \mathrm{cm}^{-3}$ thorax) to be calculated with a previously measured value of the regional lung: peripheral packed cell volume ratio in humans of $0 \cdot 9 .{ }^{13}$ Regional extravascular lung density (DEv) is calculated as the difference between the regional total lung density (DTOT) and the regional lung whole blood density. Thus DEv $=$ DTOT $-1.06 \mathrm{VB}$, where 1.06 is the density of whole blood. Values of lung density below unity result from the presence of gas within the volume element. Hence the regional gas volume (VA $; \mathrm{ml} \mathrm{cm}^{-3}$ thorax) can be calculated as $\mathrm{VA}_{\mathrm{A}}=1-\mathrm{DTOT} / 1.04$, where 1.04 is the density of gas free lung.

Measurements of ventilation ${ }^{1014}$ were made by means of continuous inhalation of the short lived inert gas isotope neon-19 $\left({ }^{19} \mathrm{Ne} ; \mathrm{T}_{1 / 2}=\right.$ $17 \cdot 4 \mathrm{~s})$ and expressed as regional ventilation per

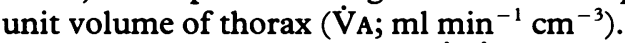

Measurements of the ratio $\dot{V} / \dot{Q}$ were made by a constant intravenous infusion of the isotope nitrogen-13 $\left({ }^{13} \mathrm{~N} ; \mathrm{T}_{1 / 2}=10\right.$ minutes; blood:gas partition coefficient $\left.\gamma_{N}=0.015\right) .^{9}$ The measurements included a correction for incomplete equilibrium of ${ }^{13} \mathrm{~N}$ in poorly ventilated regions. ${ }^{15}$

Pulmonary blood flow (Q்) was calculated from $\dot{V} / Q$ ratio and $\dot{V}_{A}$ measurements by the equation $\dot{Q}=(\dot{Q} / \dot{V}) \dot{V}_{A} ; \dot{Q}$, expressed per lung $\mathrm{g}$ tissue (Q/DEv), was also calculated.

\section{COMPENSATION FOR ABNORMAL EXPANSION}

Any regional variable that is expressed per unit volume of thorax is dependent on the expansion of the lung. Other things being equal, an increase in inflation will therefore result in a corresponding decrease in DEv. We have previously shown that, in normal non-smoking subjects, DEv and local lung size $\left(\mathbf{N}_{\mathrm{px}}{ }^{1.5}\right.$-that is, the number of picture elements of the right lung in the field of view at right heart level raised to the power of 1.5) are negatively correlated. Thus DEv is lower in subjects with bigger lungs (and therefore in taller people) ${ }^{8}$ : DEV may therefore be normalised (to an average normal lung size, $\mathrm{N}_{\mathrm{px}}^{1.5}$ (mean)) to reduce the variation and, more importantly to compensate for hyperexpansion. Thus DEV (norm) = DEV $\left[\mathrm{N}_{\mathrm{px}}{ }^{1.5} / \mathrm{N}_{\mathrm{px}}{ }^{1.5}\right.$ (mean)], where $\mathrm{N}_{\mathrm{px}}{ }^{1.5}$ (mean) is the mean value of local lung size in 15 normal nonsmoking subjects. When other physiological variables (for example, VB) were considered no such relations were found in normal non-smokers (during quiet breathing at FRC), but a change in lung inflation may be accompanied by a change in these variables. By contrast with the normalisation of DEv, therefore, the ratio $\mathrm{N}_{\mathrm{px}}{ }^{1.5} / \mathrm{N}_{\mathrm{px}}{ }^{1.5}$ (mean) is not applicable to the estimation of pathological expansion, because it does not distinguish a big lung in a large man (at normal FRC) from a lung of similar size in a small woman with a pathological increase in FRC. Fortunately, there is a significant correlation between body height and local lung size in normal subjects. A local expansion index (E) can therefore be defined as $\mathrm{N}_{\mathrm{px}}^{1.5} / \mathrm{N}_{\mathrm{px}}^{1.5}$ (pred), where $\mathbf{N}_{\mathrm{px}}^{1.5}$ (pred) is the predicted value of local lung size from body height.

PROTOCOL

The measurements were made in a single transverse slice (about $1.7 \mathrm{~cm}$ thick) through the thorax at the level of the right ventricle with the subject in the supine position. The position of the subjects was carefully maintained during the measurement. 


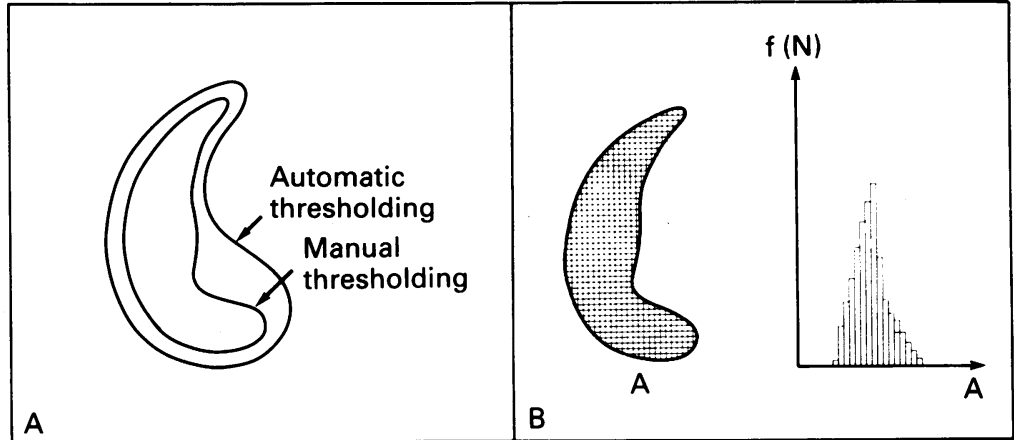

Figure 1 Data analysis (for right lung). ( $A$ ) $A$ coarse thresholding removed all pixels from the density image with values greater than $0.75 \mathrm{~g} \mathrm{~cm}^{-3}$; further thresholding was done by hand. (B) Frequency distribution pixel by pixel. $f(N)$ is the relative number of pixels within a narrow range of $A$ (sum of $f(N)=1)$.

Figure 2 Tomograms from patient 1 (type $A$ ) showing the regional distribution of

extravascular density (DEV; left upper panel), blood volume (VB; right upper), ventilation perfusion ratio ( $\dot{V} \mid \dot{Q}$; left lower), and ventilation

$(\dot{V} A ;$ right lower $)$. The

transverse section at midheart level (with the

subject in a supine

position) is viewed from

the feet of the subject, and the right lung is therefore to the left in the image. $A$ linear scale is shown with logarithmic shading. Top of the scale is $1.3 \mathrm{~g} \mathrm{~cm}$ for DEV, $1.0 \mathrm{ml} \mathrm{cm}^{-3}$ for $\dot{V} B, 4 \cdot 0$ for $\dot{V} \mid \dot{Q}$, and

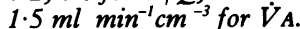
Note the high $\dot{V} \mid Q$ ratio in regions with low density, blood volume, and extravascular density.
The scanning procedure has previously been described. $^{91415}$ The study commenced with a 10 minute transmission scan to obtain regional lung density and alveolar gas volume. After this an emission scan was recorded during the last 400 seconds of a 700 second constant intravenous infusion of ${ }^{13} \mathrm{~N}(0.9-1.5 \mathrm{GBq})$ dissolved in saline. Next, a 400 second emission scan was recorded during the continuous inhalation of ${ }^{19} \mathrm{Ne}$. At the end of the study $(1 \cdot 5-2.0$ hours after the transmission scan), the subject inhaled ${ }^{11} \mathrm{CO}$ to label the red cell pool. Three to four minutes were allowed for mixing before a single 10 minute emission scan was recorded at the same level. During this scan, three venous blood samples were taken and ${ }^{11} \mathrm{CO}$ concentration in whole blood was'measured.

\section{DATA ANALYSIS}

A roughly $2-3 \mathrm{~cm}$ broad zone of the periphery of each lung and the hilar regions were removed with a thresholding procedure (fig 1A). ${ }^{8}$ Frequency distributions $f(N)$ of the various indices (relative number of pixels within a given range of the particular index (fig 1B)) were then analysed for each lung separately and the means and dispersions (SD of the distribution) were calculated. Ventilation and blood flow weighted $\dot{V} / Q$ distributions were calculated as the product of the volume weighted $\dot{\mathrm{V}} / \mathbf{Q}$ distribution (the frequency distribution of $\dot{V} / Q$ ) and the mean $V_{A}$ and $Q$ respectively of the pixels within the $\dot{V} / \dot{Q}$ range.

Finally, an analysis was made of all regions in which focal abnormalities in the $\dot{V}_{A}$ scans were seen. Mean values within these particular regions were calculated and related to the mean values of other variables within that region. The size of the regions varied between $4 \%$ and $25 \%$ of the total (left plus right) lung in the field of view.

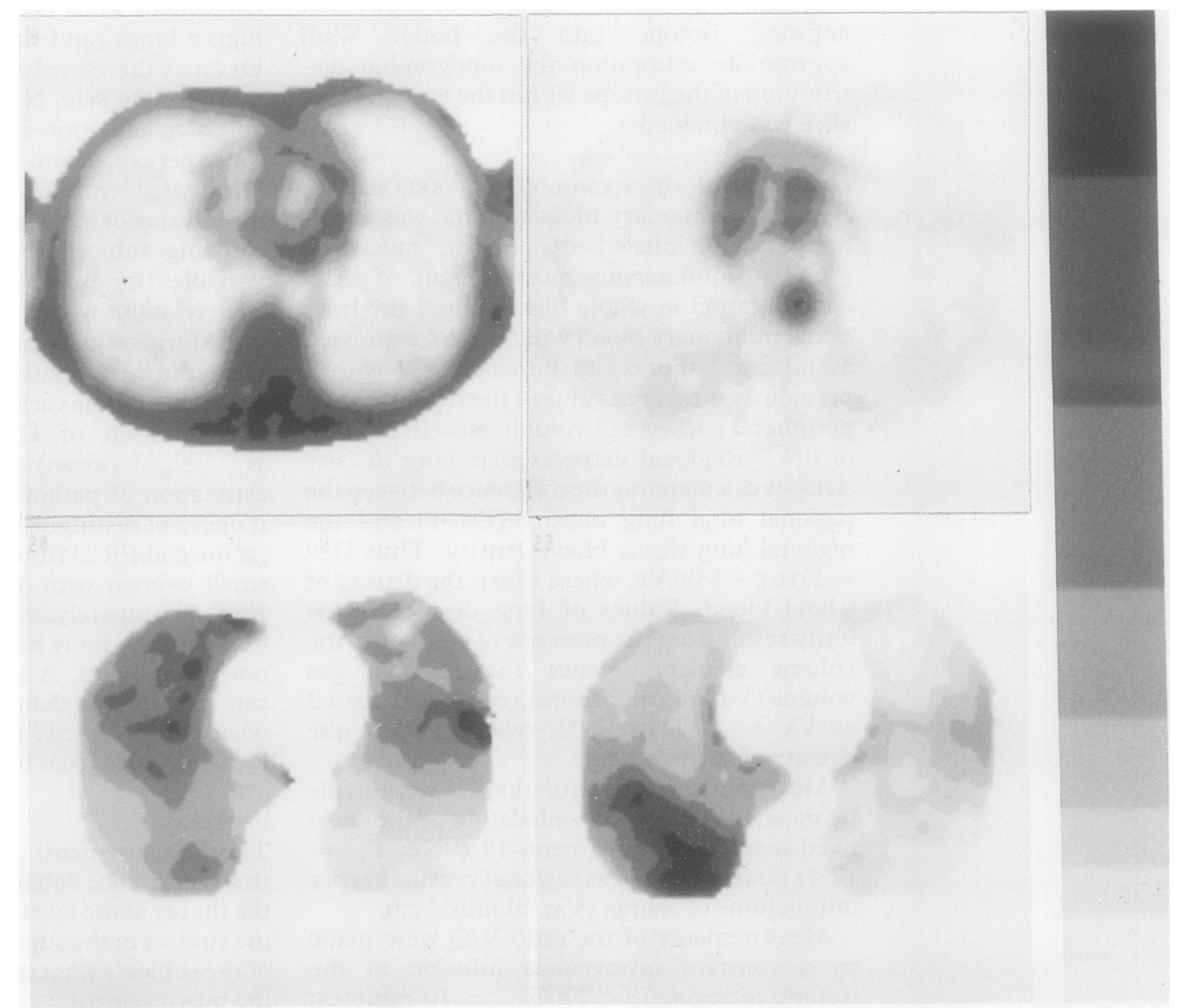


Figure 3 Tomograms from patient 10 (type $B$ ) of extravascular density (DEv; upper left; scale maximum $1.3 \mathrm{~g} \mathrm{~cm}^{-3}$ ), fractional blood volume (VB; upper right; scale maximum $1.0 \mathrm{ml} \mathrm{cm}^{-3}$ ), $\dot{V} \mid \dot{Q}$ (lower left; scale maximum 2.5) and ventilation $\left(V_{A}\right.$; lower right; scale maximum $1.5 \mathrm{ml} \mathrm{min}^{-1} \mathrm{~cm}^{-3}$ ). Note the low $\dot{V} / \dot{Q}$ ratio in the dorsal parts of the lung and the corresponding low ventilation.

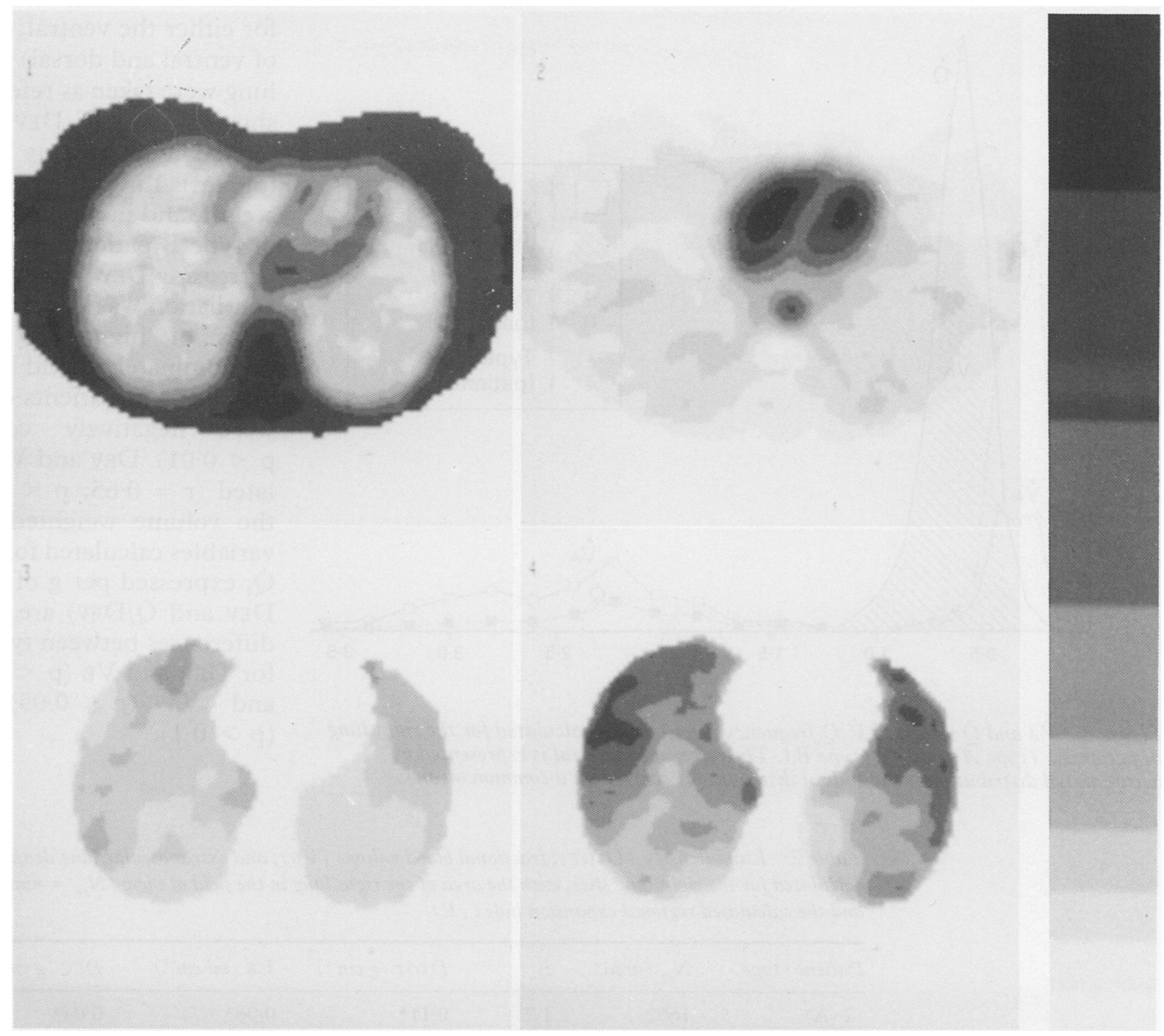

STATISTICS

Unless stated otherwise, Student's two tailed $t$ test was used for the comparison between groups. For regression analysis the equation $t$ $=\sqrt{ }\left(\mathbf{n} /\left(\mathbf{r}^{-2}-1\right)\right)$ was used, where $n$ represents degrees of freedom and $r$ is the regression coefficient. Values of $p<0.05$ were taken to be significant.

\section{Results}

COMPARISON BETWEEN TYPES A AND B

Patients 1 and 10 have been chosen to represent types $A$ and $B$ respectively. In the type $A$ patient (fig 2) extravascular lung density and blood volume (upper panels) were very low, especially in the upper, presumably emphysematous, part of the two lungs (DEV $=0.01-$ $0.02 \mathrm{~g} \mathrm{~cm}^{-3}$ and $\left.\mathrm{VB}_{\mathrm{B}}=0.02-0.03 \mathrm{ml} \mathrm{cm}^{-3}\right)$. $\dot{\mathrm{V}} / \mathbf{Q}$ (lower left panel) in these regions was high (2.5-3.5), and ventilation (lower right; $0.03 \mathrm{ml}$ $\min ^{-1} \mathrm{~cm}^{-3}$ ) and perfusion (not shown; $0.1 \mathrm{ml} \mathrm{min}^{-1} \mathrm{~cm}^{-3}$ ) were very low

The type B patient (fig 3) had a different pattern with an overall low $\dot{V} / \dot{Q}$ ratio, especially in the dorsal parts of both lungs $(0 \cdot 2-$ $0.3)$, and low ventilation $\left(0.3 \mathrm{ml} \mathrm{min}^{-1} \mathrm{~cm}^{-3}\right)$. Absolute values of DEv in these regions did not exceed the upper normal limit, but were high after correction for lung size (DEV (norm)).
Figure 4 shows the $\dot{\mathrm{V}} / \mathbf{Q}$ distributions ( $\dot{\mathrm{V}}_{\mathrm{A}}$ and $\dot{Q}$ weighted). The mode of the $\dot{V} / \dot{Q}$ distribution was shifted to the left in type $B$ and to the right in type A patients.

POOLED DATA FOR ALL PATIENTS

Mean values for right lung slice and $\dot{V} / \dot{Q}$ distributions

Tables 2 and 3 show individual data for the 10 patients as well as ranges for never smokers and smokers (including two ex-smokers) calculated as mean values for the right lung in the field of view. The regional expansion index and the size of the right lung slice $\left(\mathrm{N}_{\mathrm{px}}=\right.$ number of pixels, each being $0.32 \times 0.32 \mathrm{~cm}^{2}$ ) are also shown.

Table 3 gives values of means and dispersions (SD) of the volume weighted $\dot{V} / \dot{Q}$ distribution calculated for the right lung. Values of the ventilation and blood flow weighted $\dot{V} / \dot{Q}$ distributions were also calculated, but gave no extra information.

\section{Regions with impaired ventilation}

Figure 5 shows data for 25 regions in which ventilation was abnormal as judged by visual inspection of the scans. The variables are expressed as percentages of predicted values. Values for non-smokers, calculated separately 


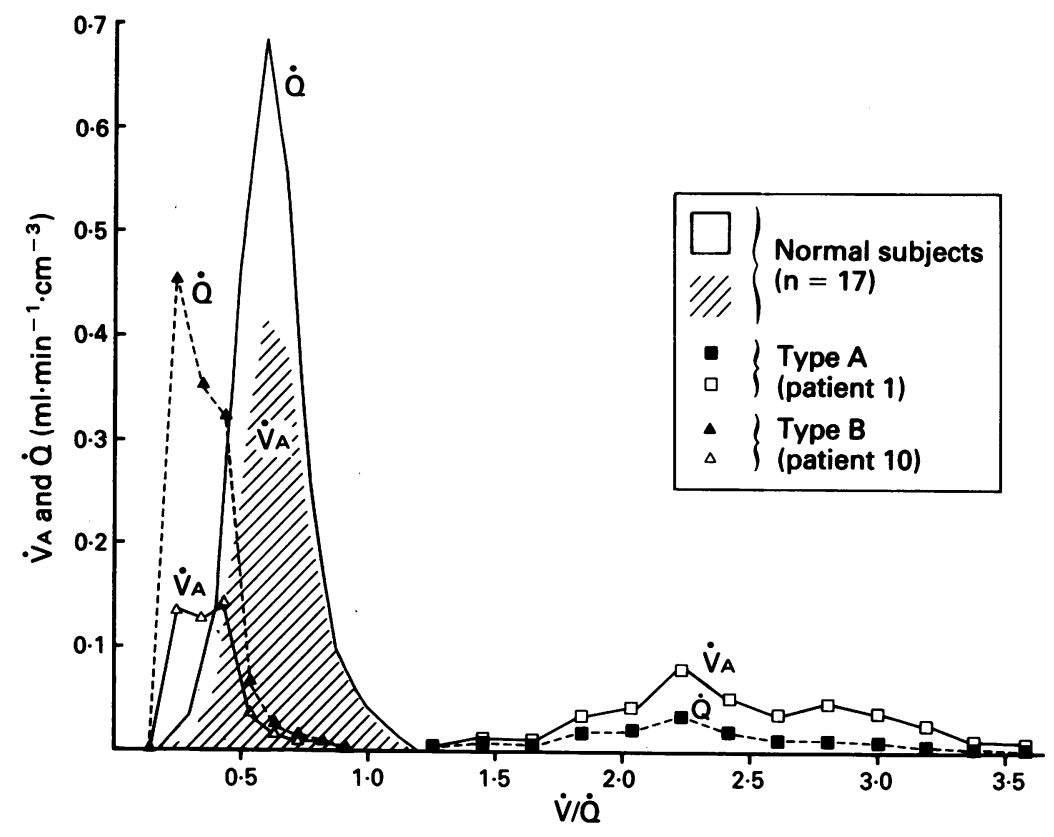

Figure $4 \dot{V}$ A and $\dot{Q}$ weighted $\dot{V} \mid \dot{Q}$ frequency distributions calculated for the right lung in patients 1 (type $A$ ) and 10 (type $B$ ). The reference material is represented by accumulated distributions (individual distributions centred on a common mean). for either the ventral, dorsal, or middle (mean of ventral and dorsal) part of the right and left lung were taken as reference values. The graph shows values of DEv, VB, $\dot{V}_{A}, \dot{Q}$, and $\dot{V} / \dot{Q}$ ranked in increasing order of DEV (top histogram). Low values of DEv were predominately found in type A patients and high values in type $B$ patients. $Q$ tended to increase with increasing $\operatorname{DEv}(r=0.59 \mathrm{p}<0.002)$ whereas ventilation was uncorrelated $(\mathrm{r}=0 \cdot 18)$. Patterns of high $\dot{V} / \dot{Q}$ with low DEv were predominately found in patients of type $A$ and vice versa in patients of type $B$. DEv and $\dot{V} / \dot{Q}$ were negatively correlated $(r=0.55$; $p<0.01)$. DEv and VB were positively correlated $(r=0.65 ; p<0.001)$. Figure 6 shows the volume weighted mean values of these variables calculated for the three types; $\dot{V}_{A}$ and Q, expressed per $g$ of extravascular lung ( $\dot{\mathrm{V}}_{\mathrm{A}} /$ $\mathrm{DEv}$ and $\mathbf{Q} / \mathrm{DEv}$ ) are also shown. Significant differences between types $A$ and $B$ were found for DEv and $V_{B}(p<0.001), Q(p<0.0025)$ and $\dot{V}_{A} \quad(p<0.05)$ but not for $\dot{V} / Q$ $(\mathrm{p}>0 \cdot 1)$.

Table 2 Lung density (DTOT), fractional blood volume ( $V B$ ), and extravascular lung density (DEV and DEV (norm)) calculated for the right lung slice, with the area of the right lung in the field of view $\left(N_{p x}=\right.$ number of pixels of the right lung) and the calculated regional expansion index $(E)$

\begin{tabular}{|c|c|c|c|c|c|c|}
\hline Patient (type) & $N_{p x}($ area $)$ & $E$ & DTOT $\left(\mathrm{g} \mathrm{cm}^{-3}\right)$ & $V B\left(\mathrm{ml} \mathrm{cm}^{-3}\right)$ & $D E V\left(\mathrm{~g} \mathrm{~cm}^{-3}\right)$ & $D E V$ (norm) $\left(\mathrm{g} \mathrm{cm}^{-3}\right)$ \\
\hline $\begin{array}{c}1(\mathrm{~A}) \\
2(\mathrm{~A}) \\
3(\mathrm{~A}) \\
4(\mathrm{~A}) \\
5(\mathrm{X}) \\
6(\mathrm{X}) \\
7(\mathrm{~B}) \\
8(\mathrm{~B}) \\
9(\mathrm{~B}) \\
10(\mathrm{~B})\end{array}$ & $\begin{array}{l}1652 \\
1705 \\
1266 \\
1679 \\
1320 \\
1205 \\
1841 \\
1541 \\
1317 \\
1370\end{array}$ & $\begin{array}{l}1.7 \\
2.0 \\
1.9 \\
1.6 \\
1.0 \\
2.0 \\
1.8 \\
2.7 \\
1.5 \\
1.9\end{array}$ & $\begin{array}{l}0 \cdot 11^{\star} \\
0 \cdot 11^{\star} \\
0 \cdot 19^{\star} \\
0 \cdot 22 \\
0 \cdot 21 \\
0 \cdot 14^{\star} \\
0 \cdot 27 \\
0 \cdot 24 \\
0 \cdot 25 \\
0 \cdot 19^{\star}\end{array}$ & $\begin{array}{l}0 \cdot 06^{\star} \\
0 \cdot 06^{\star} \\
0 \cdot 09^{\star} \\
0 \cdot 11^{\star} \\
0 \cdot 09^{\star} \\
0 \cdot 06^{\star} \\
0 \cdot 14 \\
0 \cdot 12^{\star} \\
0 \cdot 11^{\star} \\
0 \cdot 08^{\star}\end{array}$ & $\begin{array}{l}0 \cdot 04^{\star} \\
0 \cdot 04^{\star} \\
0 \cdot 10 \\
0 \cdot 11 \\
0 \cdot 11 \\
0 \cdot 08 \\
0 \cdot 13 \\
0 \cdot 11 \\
0 \cdot 14 \\
0 \cdot 11\end{array}$ & $\begin{array}{l}0.07 \\
0.08 \\
0 \cdot 11 \\
0 \cdot 18^{\star} \\
0 \cdot 13^{\star} \\
0 \cdot 08^{\star} \\
0 \cdot 25^{\star} \\
0 \cdot 17^{\star} \\
0 \cdot 16^{\star} \\
0 \cdot 13^{\star}\end{array}$ \\
\hline $\begin{array}{l}\text { Non-smokers (n } \\
\text { (mean) } \\
\text { (SD) }\end{array}$ & $\begin{array}{r}=15): \\
1208 \\
144\end{array}$ & $\begin{array}{l}1 \cdot 00 \\
0 \cdot 11\end{array}$ & $\begin{array}{l}0.276 \\
0.033\end{array}$ & $\begin{array}{l}0.163 \\
0.019\end{array}$ & $\begin{array}{l}0.103 \\
0.020\end{array}$ & $\begin{array}{l}0 \cdot 101 \\
0.016\end{array}$ \\
\hline $\begin{array}{l}\text { Smokers (n }=1 \\
\quad \text { (mean) } \\
(\mathrm{SD})\end{array}$ & $\begin{array}{r}1219 \\
125\end{array}$ & $\begin{array}{l}1 \cdot 12 \\
0 \cdot 18\end{array}$ & $\begin{array}{l}0.289 \\
0.034\end{array}$ & $\begin{array}{l}0.162 \\
0.029\end{array}$ & $\begin{array}{l}0.117 \\
0.029\end{array}$ & $\begin{array}{l}0.122 \\
0.023\end{array}$ \\
\hline
\end{tabular}

$\star$ Values outside the normal range (mean $\pm 2 \mathrm{SD}$ ) for non-smokers. Data for non-smokers are from ref 8.

Table 3 Ventilation $\left(\dot{V}_{A}\right)$, pulmonary blood flow ( $\left.\dot{Q}\right)$, and $\dot{V} \mid \dot{Q}$ calculated for the right lung slice. Values are also expressed per $g$ lung tissue ( $\dot{V} A \mid D E V$ and $\dot{Q} / D E V)$; extravascular lung density $(D E V) /(\dot{V} / \dot{Q})$ is presented for the total lung slice (right and left)

\begin{tabular}{|c|c|c|c|c|c|c|c|}
\hline Patient & $\begin{array}{l}\dot{V}_{A} \\
\left(m l \min ^{-1} \mathrm{~cm}^{-3}\right)\end{array}$ & $\begin{array}{l}\dot{V} A / D E V \\
\left(m l \min ^{-1} g^{-1}\right)\end{array}$ & $\dot{Q}\left(m l \min ^{-1} \mathrm{~cm}^{-3}\right)$ & $\begin{array}{l}\dot{Q} / D E V \\
\left(m l \min g^{-1}\right)\end{array}$ & $\dot{V} \mid \dot{Q}$ & $S D(\dot{V} \mid \dot{Q})$ & $\begin{array}{l}\operatorname{DEV} /(\dot{V} \mid \dot{Q}) \\
\left(\mathrm{g} \mathrm{cm}^{-3}\right)\end{array}$ \\
\hline $\begin{array}{r}1(\mathbf{A}) \\
2(\mathbf{A}) \\
3(\mathbf{A}) \\
4(\mathbf{A}) \\
5(\mathbf{X}) \\
6(\mathrm{X}) \\
7(\mathbf{B}) \\
8(\mathbf{B}) \\
9(\mathbf{B}) \\
10(\mathbf{B})\end{array}$ & $\begin{array}{l}0.61^{\star} \\
0 \cdot 37^{\star} \\
0.89 \\
0 \cdot 75^{\star} \\
0.40^{\star} \\
0.37^{\star} \\
1 \cdot 19 \\
1.28 \\
1.07 \\
0.50^{\star}\end{array}$ & $\begin{array}{c}21 \cdot 8 \\
10 \cdot 1 \\
9 \cdot 2 \\
9 \cdot 0 \\
3 \cdot 8^{\star} \\
4 \cdot 9^{\star} \\
10 \cdot 3 \\
12 \cdot 2 \\
8 \cdot 5 \\
5 \cdot 1^{\star}\end{array}$ & $\begin{array}{l}0 \cdot 2^{\star} \\
0 \cdot 4^{\star} \\
1 \cdot 4^{4} \\
0 \cdot 9^{\star} \\
0 \cdot 4^{\star} \\
0 \cdot 6^{\star} \\
1 \cdot 4^{-} \\
1 \cdot 8 \\
2 \cdot 6 \\
1 \cdot 2\end{array}$ & $\begin{array}{c}7 \cdot 4^{\star} \\
9.6 \\
14 \cdot 2 \\
9.9 \\
3.7^{\star} \\
7.9 \\
11.6 \\
16 \cdot 2 \\
18 \cdot 4 \\
12.3\end{array}$ & $\begin{array}{l}2.92^{\star} \\
0.92 \\
0.75 \\
0.76 \\
0.96 \\
0.55 \\
0.86 \\
0.81 \\
0.53^{\star} \\
0.40^{\star}\end{array}$ & $\begin{array}{l}0 \cdot 61^{\star} \\
0 \cdot 34^{\star} \\
0 \cdot 42^{\star} \\
0 \cdot 49^{\star} \\
0 \cdot 26^{\star} \\
0 \cdot 16 \\
0 \cdot 24 \\
0 \cdot 27^{\star} \\
0 \cdot 23 \\
0 \cdot 13\end{array}$ & $\begin{array}{l}0.02^{\star} \\
0.05^{\star} \\
0 \cdot 16 \\
0 \cdot 14 \\
0 \cdot 14 \\
0 \cdot 16 \\
0 \cdot 17 \\
0 \cdot 20 \\
0 \cdot 28 \\
0.33\end{array}$ \\
\hline $\begin{array}{c}\text { Non-smo } \\
\text { (mean) } \\
\text { Limit }\end{array}$ & $\begin{array}{l}\text { kers }(n=8) \\
1.43 \\
0.80\end{array}$ & $\begin{array}{r}13 \cdot 3 \\
6 \cdot 4\end{array}$ & $\begin{array}{l}1 \cdot 87 \\
0 \cdot 80\end{array}$ & $\begin{array}{r}17 \cdot 1 \\
7 \cdot 7\end{array}$ & $\begin{array}{l}0.81 \\
0 \cdot 14 \ddagger\end{array}$ & $\begin{array}{l}0.147 \\
0.050 \ddagger\end{array}$ & $\begin{array}{l}0 \cdot 18 \\
0 \cdot 10\end{array}$ \\
\hline $\begin{array}{c}\text { Smokers } \\
\text { (mean) } \\
\text { Limit }\end{array}$ & $\begin{array}{l}(n=9) \dagger \\
1.34 \\
0.73\end{array}$ & $\begin{array}{r}10 \cdot 5 \\
4 \cdot 2\end{array}$ & $\begin{array}{l}2 \cdot 2 \\
1 \cdot 1\end{array}$ & $\begin{array}{r}16 \cdot 7 \\
6 \cdot 9\end{array}$ & $\begin{array}{l}0.66 \\
0.12 \ddagger\end{array}$ & $\begin{array}{l}0.125 \\
0.039 \ddagger\end{array}$ & $\begin{array}{l}0.24 \\
0 \cdot 14\end{array}$ \\
\hline
\end{tabular}

*Values outside the normal non-smoking limits (below the lower limit given in the table or outside \pm 2 SD).

†Seven never smokers plus two ex-smokers; limit-the lowest individual observation ( $\ddagger S D)$; $\dot{V} / Q)-$ mean of the volume weighted $\mathbf{V} / Q$ distribution; SD $(\dot{V} / Q)$-its dispersion. 

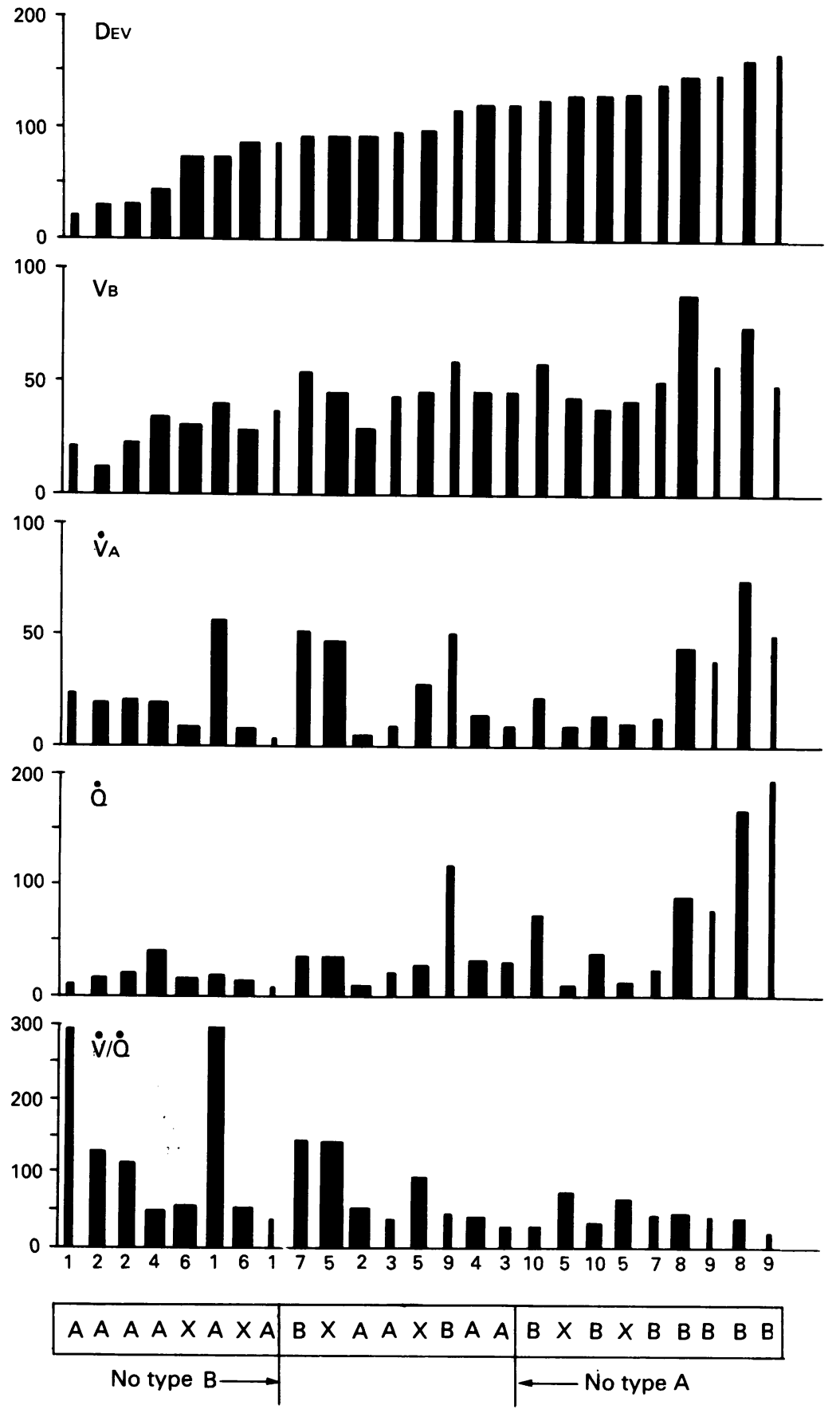

Figure 5 Values of variables calculated for irregular regions ranked in order of increasing values of extravascular lung density (DEV) expressed as \% predicted (see text). The width of the bars are proportional to size of region (\% of size of right plus left lung slice). $V_{B}-$ fractional pulmonary blood volume; $\dot{V}_{A-v e n t i l a t i o n ;}$ $Q-$ perfusion. p $<0.05)$ and no significant correlations were found between $V_{B}, \dot{Q}$, or $\dot{V}_{A}$ and Kco. FRC, TLC, and RV were not correlated with the expansion index.

\section{Discusssion}

Positron emission tomography has provided new information. As well as regional ventilation, perfusion, and their ratio, quantitative measurements of vascular and extravascular density have been obtained as described by Rhodes et al. ${ }^{7}$ Structure-function relation at a local level have been explored by determining the correlations of tissue density and blood volumes with $\dot{\mathrm{V}} / \dot{\mathrm{Q}}$ and blood flow in regions with impaired ventilation.

\section{REGIONAL STRUCTURE}

Tissue density

As expected from the definition of emphysema, extravascular density was generally lower in the type A patients compared with the type B patients, even after correcting for lung size including hyperinflation (DEv (norm)). Nevertheless, mean extravascular density in absolute units, calculated for the whole lung section studied, was below the normal range only in two type A patients. Thirty five per cent (by volume) of the regions of abnormal ventilation in the type A patients had values below the normal range $\left(0.06-0.14 \mathrm{~g} \mathrm{~cm}^{-3}\right.$ thorax). It is interesting that the normalised extravascular density was generally within the normal range (type A) or above it (type B), an indication that lung tissue weight is normal in type $A$ and abnormally high in type $B$ patients. When emphysema is assessed by $x$ ray computed tomography ${ }^{1-3}$ total lung density (not extravascular density) is measured and there is no correction for inflation. Table 2 shows that three of the four type A patients and one each of type $\mathrm{X}$ and type $\mathrm{B}$ patients had abnormally low values of total lung density. The product of the ratio DEv/VA (right plus left lung slice) and supine FRC (table 1), assuming one midthoracic slice is a reasonable sample of the whole lung, gave a tissue weight of $140 \%$ predicted for the type A patients, which is not low, and $240 \%$ for the type B patients, which is probably high. Published information on this subject is, however, scarce. ${ }^{5}$

\section{VASCULAR DENSITY}

The low values for blood volume in the type A patients are probably caused by vascular destruction (note low DEv and KCO), although hyperexpansion may also be a significant factor. In type B patients hyperexpansion is probably the main cause of the low values of fractional blood volume because absolute blood volume is only slightly lower in these patients than in normal subjects. In fact, regional blood flow is often normal in type B patients, ${ }^{15}$ an indication of normal vasculature. When corrected for expansion, blood volume was within or above the normal range in the type $B$ patients and, on, average, $60 \%$ higher than in the type $\mathrm{A}$ patients. 


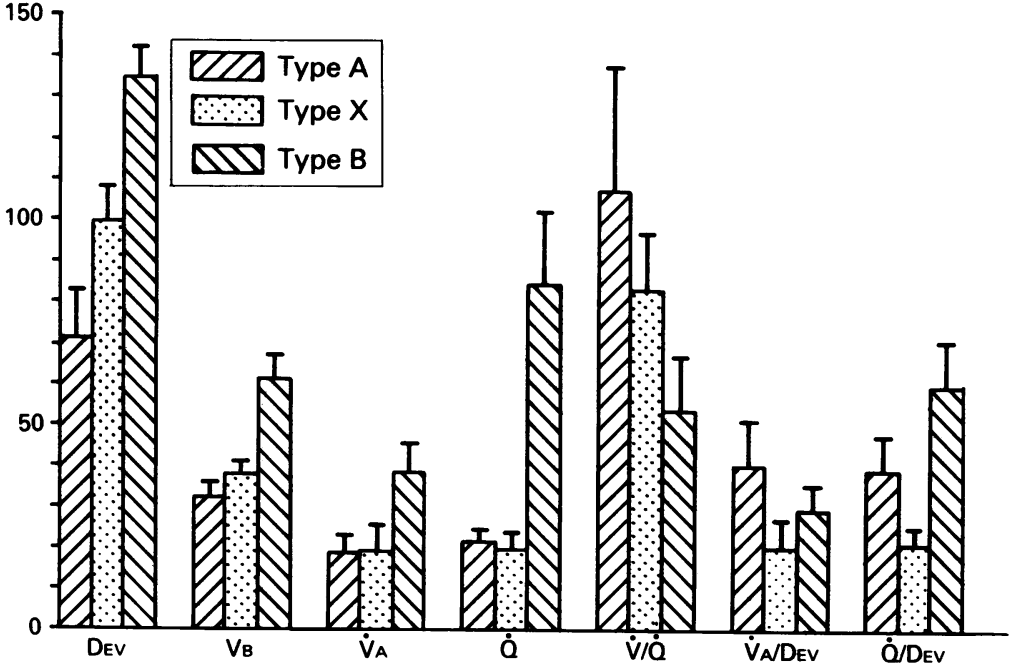

Figure 6 Volume weighted mean values of $D_{E V}, V_{B}, \dot{V}_{A}, \dot{Q}$, and $\dot{V} \mid \dot{Q}$ (from fig. 5) calculated for the three types of patients with chronic obstructive lung disease. Ventilation and blood flow per $g$ extravascular lung ( $\dot{V}_{A} / D E V$ and $\left.Q / D E V\right)$ are also shown. The values are expressed as \% predicted and vertical bars represent one $S E$.

REGIONAL GAS EXCHANGE

Using the multiple inert gas elimination technique Wagner et al showed that seven of eight type A patients and also eight of 12 type $B$ patients had normal or high ventilation weighted distributions centred on a normal or high $\dot{V} / \mathbf{Q}$ mode. Blood flow weighted $\dot{V} / \mathbf{Q}$ distributions that were centred on a low mode were found almost exclusively in patients of type $B$ and type $\mathrm{X}$. We found, similarly, abnormally low mean values of $\dot{V} / Q$ only in patients of type $B$ (patients 9 and 10). Nevertheless, local regions with abnormally low values of $\dot{\mathrm{V}} / \mathbf{Q}$ were found in nearly all patients (fig 5).

Ventilation and blood flow weighted distributions were also calculated but had configurations similar to each other (and to the volume weighted distribution) and provided no extra information (see examples in fig 4).

REGIONAL STRUCTURE-FUNCTION CORRELATION In type A patients (for example, patient 1, fig 2), low values of extravascular density and high values of $\dot{V} / Q$ were found in regions with impaired ventilation. By contrast, type B patients (patient 10, fig 3) had regions with high extravascular density and low $\dot{V} / Q$. Similar high and low $\dot{V} / Q$ ratios have been shown by the multiple inert gas elimination technique, ${ }^{6}$ with a tendency for patients of type $A$ to have a large proportion of ventilation going to units with high $\dot{V} / Q$ ratios, and for patients of type $B$ to have a large proportion of blood flow going to low $\dot{V} / Q$ regions. In as much as emphysema is associated with low density on computed tomograms $\mathrm{s}^{1-3}$ a negative correlation between the $\dot{V} / Q$ ratio and extravascular lung density (fig 5 ) is not surprising.

High $\dot{V} / Q$ regions were found in a type $B$ patient in only one out of six instances (fig 5). By contrast, low $\dot{\mathrm{V}} / \dot{Q}$ regions were distributed evenly between types $A, X$, and $B$. In six regions (fig 5; patients 8,9 , and 10 , all type $B$ ) low $\dot{V} / Q$ values were associated with normal or almost normal local blood flow and normal extravascular tissue density. This suggests that bronchial narrowing or obstruction is the predominant cause of the abnormal local gas exchange in these patients and that they continue to perfuse poorly ventilated regions with a relative lack of vascular compensation. At the other extreme, the low $\dot{\mathbf{V}} / \mathbf{Q}$ regions of patients 4 and 6 (fig 5), classified as types $A$ and $X$ respectively, were associated with low local blood flow and low extravascular density suggestive of emphysema. Overall, the ratio of blood flow to extravascular density was similar in types A and B (fig 6), implying that loss of vascular structures runs in parallel with tissue destruction in emphysema.

\section{REGIONAL $V$ GLOBAL STRUCTURE-FUNCTION} CORRELATION

Several morphometric estimates of emphysema from lobes or lungs resected for lung tumours in relation to computed tomographic density have been published. ${ }^{1-4}$ In the most extensive study, Gould et $a l^{2}$ found that computed tomographic densities in the lowest fifth percentile of the density histogram correlated closely with the morphometric emphysema score and this score correlated with TLCo/VA. We found a good correlation between Kco (TLCo/VA) and the ratio $\operatorname{DEv} /(\dot{V} / \dot{Q})$ which discriminated between the type $A$ and $B$ patients (table 3 ).

\section{Conclusions}

Using positron emission tomography and sampling only a single transaxial cross section, we found quite striking differences between patients with chronic obstructive pulmonary disease of type A (with low Kco) and type B (with high $\mathrm{KCO}$ ) that are associated with high and low degrees of morphometric emphysema. Type A patients had lower tissue density, lower peripheral vascular volume, lower blood flow per $\mathrm{cm}^{3}$ thorax, and higher $\dot{V} / Q$ than patients with type B. For type B patients there was a high tissue density after correction for hyperinflation (suggesting inflammation or oedema), and a lower ventilation but higher blood flow per tissue (fig 6). These findings further support the notion that bronchial or bronchiolar inflammation or oedema predominate in some cases of chronic obstructive lung disease and that alveolar destruction is the major feature of others.

We thank Mr D D Vonberg for support and the staff at the Cyclotron Unit for technical assistance. This study was supported partly by Draco Foundation, by Thorsten Birger Segerfalk Foundation for Medical Research and Education, by the Swedish National Association against Chest and Heart Diseases, and by the Swedish Medical Research Council, grant 02872.

1 Bergin C, Müller N, Nichols DM, Lillington G, Hogg JC, Mullen B, et al. The diagnosis of emphysema: a computed tomography-pathologic correlation. Am Rev Respir Dis 1986;133:541-6.

2 Gould GA, Macnee W, Maclean A, Warren PM, Redpath A, Best JJK, et al. CT measurements of lung density in life can quantitate distal airspace enlargement - an essential defining feature of human emphysema. Am Rev Respir Dis 1988;137:380-92.

3 Müller NL, Staples CA, Miller RR, Abboud RT “Density mask": an objective method to quantitate emphysema 
using computed tomography. Chest 1988; 94:782-7.

4 Morrison NJ, Abboud RT, Ramadan F, Miller RR, Gibson NN, Evans KG, et al. Comparison of single breath carbon monoxide diffusing capacity and pressure-volume curves in detecting emphysema. Am Rev Respir Dis 1989;139: 1179-87.

5 Petty TL, Silvers GW, Stanford RE. Mild emphysema is associated with reduced elastic recoil and increased lung size but not with airflow limitation. Am Rev Respir Dis 1987;136:867-71.

6 Wagner PD, Dantzker DR, Dueck R, Clausen JL, West JB. Ventilation-perfusion inequality in chronic obstructive pulmonary. J Clin Invest 1977;59:203-16

7 Rhodes CG, Wollmer PE, Fazio F, Jones T. Quantitative measurement of regional extravascular lung density using positron emission and transmission tomography. J Compositron emission and transmission Tomogr 1981;5:783-91.

8 Brudin LH, Rhodes CG, Valind SO, Wollmer PE, Hughes JMB. Regional lung density and blood volume in nonsmoking and smoking subjects measured by PET. J Appl Physiol 1987;63:1324-34.

9 Rhodes CG, Valind SO, Brudin LH, Wollmer PE, Jones T, Buckingham PD, et al. Quantification of regional $\dot{V} / \mathcal{Q}$ ratios in humans by use of PET: II. Procedure and normal values. J Appl Physiol 1989;66:1905-13.

10 Valind SO, Rhodes CG, Jonson B. Quantification of regional ventilation in man using a short-lived radiotracerTheoretical evaluation of the steady-state model. $J$ Nucl Med 1987;28:1144-54.

11 Comroe JH Jr, Forster RE, Dubrois AB, Briscoe WA, Carlsen $\mathrm{E}$. The lung: clinical physiology and pulmonary function tests, 2nd ed. Chicago: Year Book Medical Publishers, 1962:325.

12 Burrows B, Fletcher CM, Heard BE, Jones NL, Wootliff JS The emphysematous and bronchial types of chronic airways obstruction. A clinicopathological study of patients in London and Chicago. Lancet 1966; i:830-5.

13 Brudin LH, Valind SO, Rhodes CG, Turton DR, Hughes JMB. Regional lung hematocrit in humans using positron emission tomography. J Appl Physiol 1986;60:1155-63.

14 Valind SO. Ventilation and ventilation/perfusion ratios: Measurements of regional lung function based on positron emission tomography (Ph D thesis). Lund: University of Lund, Sweden, 1989.

15 Brudin LH, Valind S-O, Rhodes CG. Error analysis of combined measurements of regional ventilation and $\dot{V} / Q$ ratio using positron emission tomography. Phys Med Biol 1992;37:1077-93. 